\section{Desafios para a universalização da genética clínica: o caso brasileiro}

\author{
Maria Concepción Novoa ${ }^{1}$ \\ e Teresinha Fróes Burnham ${ }^{1}$
}

Como citar: Novoa MC, Fróes Burnham T. Desafios para a universalização da genética clínica: o caso brasileiro. Rev Panam Salud Publica. 2011;29(1):61-8.

\section{SINOPSE}

Este artigo aborda as dificuldades de inserir a genética médica como parte do Sistema Único de Saúde (SUS) no Brasil. Em 2009, foi instituída no Brasil a Política Nacional de Atenção Integral em Genética Médica, cujo pilar central seria o aconselhamento genético. Porém, são problemas estratégicos para a implementação dessa política a falta de programas de formação em aconselhamento genético, o desconhecimento acerca de quantos profissionais existem para prestar esse aconselhamento e o provável baixo número de profissionais disponíveis. É desejável uma atuação conjunta dos Ministérios da Saúde e da Educação para ampliar a educação em genética e a formação em aconselhamento genético para todas as profissões no campo da saúde. Além disso,é essencial a inclusão da genética em programas como o Saúde da Família, que permitirá um mapeamento da incidência das doenças genéticas no país e a implementação de aconselhamento genético apesar do grande território e da heterogeneidade populacional do Brasil. Finalmente, a inserção da genética médica no SUS depende do engajamento de profissionais médicos e não médicos no trabalho em equipes horizontais, com alteração da tradicional hierarquia da atenção à saúde.

Palavras-chave: genética médica; aconselhamento genético; Sistema Unnico de Saúde; formação de recursos humanos; programas nacionais de saúde; Brasil.

\footnotetext{
1 Universidade Federal da Bahia (UFBA), Faculdade de Educação, Rede Cooperativa de Pesquisa e Intervenção em (In)formação, Currículo e Trabalho - REDPECT, Salvador, BA, Brasil. Correspondência: Maria Concepción Novoa, novoabr@yahoo.com
}

Uma das facetas menos estudadas com relação ao espantoso desenvolvimento do conhecimento da genética humana e sua aplicação na medicina é aquela relacionada com maturidade social e cidadania. Em tese defendida em 2008 (1), argumenta-se que o conhecimento em genética conduz ao enfrentamento de novos paradigmas e da nova realidade científica sob diferentes aspectos, muitos deles relacionados ao funcionamento da sociedade e à maturidade de suas instituições formativas, representativas, legislativas, judiciárias e executivas. Mesmo no processo de construção do saber, a área da genética já nasce polêmica: como experimentar? Que seres vivos ou espécies devem ser usados em experiências que dizem respeito a seres humanos? Até onde se podem usar e divulgar as informações obtidas de pacientes afetados por uma doença? Quem deve lucrar com as descobertas? A quem pertence o genótipo mutante? Essas e outras questões são suscitadas pela natureza do conhecimento genético, que lida com questões profundas da existência, da integridade individual e social e da ética.

O Brasil, reconhecidamente pioneiro, na América Latina, no desenvolvimento de pesquisas em genética humana, área na qual obteve notoriedade já no início da década de 1950, com os trabalhos de FreireMaia, Frota-Pessoa e Beiguelman (2), possui uma legislação social avançada na área de saúde. Por determinação da Constituição vigente a partir de 1988 (3), a saúde no Brasil é "um direito de todos e dever do Estado, garantido mediante políticas sociais e econômicas que visem à redução do risco de doença e de outros agravos e ao acesso universal e igualitário às ações e serviços para sua promoção, proteção e recuperação".

Cabe destacar que as políticas de saúde, tal qual foram incluídas na Carta Magna, representam o estágio de amadurecimento, naquela época, do pensamento filosófico-social do conceito de assistência à saúde. Em outras palavras, a sociedade brasileira, através das suas lideranças na área da sociologia da saúde, da saúde comunitária e das comunidades, passava por um longo e complexo processo de modificação dos conceitos de saúde e doença, de assistência à saúde, de observação e modificação de modelos ora vigentes, ora em desuso, ao longo do tempo.

Após 1988, uma vez definida a política nacional de saúde, iniciou-se a construção do arcabouço legal que permitiu a sua aplicação em todo o território nacional. Em 1990 foi aprovada a lei orgânica da saúde (lei 8080 revisada e publicada posteriormente como lei 8 142/ 1990). Posteriormente, o poder executivo passou a regulamentar a aplicação da lei através de portarias chamadas de normas operacionais básicas (NOB) e normas operacionais de assistência à saúde (NOAS) (4). Essas normas serviram para incentivar a descen- 
tralização do sistema, diferenciar gestão de gerência e definir as áreas de aplicação das políticas e as responsabilidades, atribuições e condições para a gestão. Nesse contexto foram criados os conselhos estaduais e municipais de saúde e definida a sua atuação como pré-requisito para a gestão. Acrescente-se a essas normas a emenda constitucional $\mathrm{n}^{\circ} 29$, que assegurou os recursos mínimos para o financiamento das ações e serviços públicos de saúde. Tem-se assim o conjunto legislativo que rege as ações em saúde.

Concomitantemente ao desenvolvimento de normas legais que garantiram e orientaram a gestão, a operacionalização e o financiamento do Sistema Único de Saúde (SUS) no Brasil, o mundo passou por um avanço inédito na área da genética humana. Esse avanço abriu novos espaços para a aplicação da genética na área da saúde, revolucionando o conhecimento sobre causa e efeito das doenças e métodos de diagnóstico e criando novas e inéditas terapias. Ao mesmo tempo, as técnicas de diagnóstico por imagem também passaram por um avanço, que permitiu uma visualização muito mais nítida de problemas morfológicos e estruturais do corpo humano, inclusive do concepto.

Embora as novas possibilidades de cura, de longevidade sadia, de recuperação de propriedades perdidas, de desenvolvimento de capacidades antes deficientes, tenham iluminado com um clarão o campo da saúde, sua real aplicação é limitada. As terapias com resultados concretos são poucas, porém, por serem altamente significativas na mudança da qualidade e duração de vida das pessoas afetadas, passaram a ser demandadas. Na ausência de acesso às novas terapias, seja por causa do seu alto custo ou devido à sua não disponibilidade no Brasil, muitas pessoas passaram a acionar o poder judiciário, com base na Constituição. Essa situação reflete, de um lado, a visão paternalista do Estado por parte da sociedade, e de outro, a falta de regras para regular a assistência em genética no País.

Sensível às reivindicações de geneticistas médicos e de associações de familiares e de pessoas afetadas por doenças genéticas, o poder executivo publicou, em 20 de janeiro de 2009, a portaria 81, que instituiu, no âmbito do SUS, a Política Nacional de Atenção Integral em Genética Clínica. É importante ressaltar que, no preâmbulo justificatório da emissão da portaria, o aconselhamento genético foi citado como "pilar central da atenção à saúde em genética clínica" e, mais ainda, como um procedimento que "deve ser garantido a todos os indivíduos e famílias sob risco de anomalia congênita ou doença genética" (5). Entretanto, são inúmeras as dificuldades associadas a essas asserções.

\section{DIFICULDADES CONCEITUAIS, EDUCACIONAIS E LEGAIS}

Ao tomar e oficializar a decisão política que prevê a garantia de serviços de genética para a população, o governo brasileiro criou uma situação de impasse. Como disponibilizar, em mais de 5 mil municípios brasileiros, para uma população maior do que 180 milhões de pessoas (6), a atenção básica na área de ge- nética? Surge aqui o primeiro entrave, que diz respeito a pessoal especializado: geneticistas. Existe uma gritante falta de dados sobre os profissionais capacitados a exercer a atividade de geneticista e sobre os profissionais que efetivamente trabalham como geneticistas, nas universidades, consultórios, convênios médicos e instituições públicas de saúde. O Conselho Nacional de Secretários de Saúde (CONASS) registrava, em 2007 (7), a existência de 156 médicos geneticistas distribuídos desigualmente no País (128 nas regiões Sul e Sudeste, 19 no Nordeste, 8 no Centro-Oeste e apenas 1 no Norte). O que dizer dos profissionais não médicos envolvidos no atendimento a pacientes da área de genética? Quantos são? Onde estão? Qual sua área de formação? Em quais áreas eles atuam? Não existem informações a esse respeito.

Os levantamentos existentes quanto aos serviços de genética e aos profissionais de saúde neles envolvidos são extremamente limitados e carregam um viés cultural que impede que os dados reflitam a realidade; trata-se do contencioso sobre quem deve fazer o aconselhamento genético. Para evitar o conflito, o problema tem sido simplesmente ignorado. Mesmo nas sociedades que agrupam geneticistas (Sociedade Brasileira de Genética e Sociedade Brasileira de Genética Médica), não há, no formulário de inscrição, a opção "aconselhamento genético" para descrever a atividade profissional. Em 1997, Brunoni (8) publicou os resultados de uma pesquisa que identificou 33 serviços de genética. Salzano, 5 anos depois (9), calculou que o número de laboratórios particulares deveria ser bem maior, mais do que dobrando esse número. Horovitz et al. (10) confirmaram essa percepção, registrando 56 serviços de genética no País, sendo 33 com atendimento clínico e laboratorial, $15 \mathrm{com}$ atendimento somente clínico e $8 \mathrm{com}$ atendimento somente laboratorial. A maioria desses serviços funcionava nas capitais dos estados. A fragilidade desses dados é reconhecida pelos próprios autores. Apesar do trabalho de Brunoni ser de 1997, quando já estavam em atividade diversos laboratórios de genética particulares e um pequeno número de geneticistas atuava em consultórios particulares, o único serviço não ligado a uma instituição de ensino superior listado no relato daquele autor é o serviço da Associação de Pais e Amigos dos Excepcionais (APAE) de São Paulo. Quase metade dos serviços de genética listados naquela época encontravam-se no Estado de São Paulo.

A primeira dificuldade para implementar e oferecer serviços de aconselhamento genético poderia, então, ser resumida da seguinte forma: desconhecimento por parte das autoridades de saúde, federais e estaduais, e das próprias associações profissionais, quanto ao número de profissionais de saúde, médicos, biólogos, odontólogos, enfermeiros, farmacêuticos, nutricionistas, psicólogos, biomédicos, fisioterapeutas e terapeutas ocupacionais atuando efetivamente na área de genética, inclusive realizando aconselhamento genético, seja no âmbito público ou no âmbito privado. Vale ressaltar que dentre as áreas de atuação definidas pelos conselhos federais de biologia (11), biomedicina 
(12) e enfermagem (13) está contemplada a atividade de aconselhamento genético para seus membros.

Esse fato traz à tona a fragilidade do aconselhamento genético, reconhecido, oficialmente, como pilar central da atenção à saúde em genética clínica. A área de aconselhamento faz parte da formação dos médicos com especialização em genética. A Sociedade Brasileira de Genética, que agrupa geneticistas humanos nãomédicos, além de geneticistas de outras áreas, exige conhecimentos de aconselhamento genético para a concessão de título de especialista em citogenética humana ou biologia molecular, mas não fornece título de conselheiro genético (14). Além disso, muitos dos profissionais de saúde com título de especialista em genética clínica não praticam o aconselhamento genético. Muitos deles, inclusive médicos, optam por não fazê-lo, pela grande exigência de tempo e outros motivos. Pode-se supor, portanto, que dos 156 médicos geneticistas mencionados pelo CONASS, pelo menos uma parte não atue como conselheiro genético. Ou seja, o número de médicos conselheiros genéticos é provavelmente muito pequeno.

O aconselhamento genético é um valioso procedimento, que permite uma conexão entre a ciência e a sociedade. Por ser um espaço no qual todos os participantes aprendem, deixando aflorar sua bagagem cultural, suas tradições, seu preparo educacional e de vida, suas crenças, prioridades e medos, o aconselhamento genético é um acontecimento especial. Nele, as pessoas aprendem sobre si próprias e tomam decisões que transcendem o espaço médico. É, por isso mesmo, uma área bastante complexa, cuja epistemologia se fundamenta não somente no conhecimento científico, mas também na psicologia, sociologia, filosofia, teologia, antropologia e comunicação. Diversos países, como Estados Unidos, Canadá, Inglaterra e Austrália consideram o aconselhamento genético uma área específica, para a qual se exige uma preparação também específica, em nível de especialização ou mestrado. Nesses países, a profissão de conselheiro genético é regulamentada, tem seu conselho e associação de classe e normas específicas para acreditação e formação (15-18).

A mais recente definição de aconselhamento genético é fornecida pela National Society of Genetic Counselors, dos Estados Unidos (19). Essa definição estabelece que o aconselhamento genético é o processo de ajudar as pessoas a compreender e se adaptar às implicações médicas, psicológicas e familiares decorrentes da contribuição genética para a enfermidade. Desde essa perspectiva, o aconselhamento genético engloba a interpretação das histórias clínicas e familiares para avaliar a probabilidade de ocorrência ou recorrência da doença; a educação a respeito de hereditariedade, exames, tratamento, prevenção, ajuda e pesquisa; e o aconselhamento adequado para promover escolhas conscientes e adaptação à condição de risco.

No Brasil, mesmo neste início do século XXI, a discussão ameaça não sair do âmbito coorporativo, no qual se advoga que somente médicos podem fazer aconselhamento genético, apesar das manifestações, mesmo que tímidas (20), ou explícitas, porém com claro viés coorporativo (21), incentivando a prática do aconselhamento por profissionais não médicos. Vale lembrar que, no Brasil, os biólogos se situam entre os pioneiros a praticar o aconselhamento genético, e que muitos profissionais não médicos o praticam no ambiente das instituições de assistência à saúde ligadas a instituições de ensino superior, a projetos de pesquisa e a programas de pós-graduação stricto sensu. Quem sai dessa esfera dificilmente consegue fazer aquilo para que foi preparado. Essa fase de transição, que inclui atritos interprofissionais, já foi vivenciada por outros países no caminho para a organização e a normatização da profissão de conselheiro genético, como relata Kenen (22). O fato de, no nosso País, os atritos surgirem, tornarem-se visíveis e estarem chegando, mesmo que indiretamente, ao poder legislativo e ao judiciário, é alvissareiro, pois tais atritos surgem como indicadores da necessidade da regulamentação legal da atividade de geneticista e conselheiro genético, favorecendo a discussão necessária para um consenso. $\mathrm{O}$ mesmo pode-se inferir da movimentação da sociedade através das organizações não-governamentais que congregam pessoas afetadas, seus familiares e amigos.

A segunda dificuldade estratégica à oferta de serviços de aconselhamento genético seria reconhecer o aconselhamento como área de atuação de um profissional de saúde devidamente preparado para tal, incentivando as associações a estabelecerem um currículo mínimo para a formação do conselheiro genético. Por outro lado, desde 1968 se formam no Brasil mestres e doutores em genética humana, com capacitação para fazer aconselhamento genético e que hoje não têm campo de trabalho fora da universidade. Como esperar que o Estado abra vagas para conselheiro genético se a profissão ainda não existe?

Uma das mais sérias consequências da falta de normatização e regulamentação é o desperdício de recursos financeiros investidos na formação de uma força de trabalho especializada que não encontra colocação, especialmente por falta de iniciativa política, com a qual as próprias associações profissionais são coniventes, enquanto as associações de pessoas afetadas permanecem passivas por não terem nem a visão, nem a força de reivindicação.

Na esfera da medicina privada ou suplementar, os convênios médicos eventualmente descobrirão que a área da genética, contrário ao que se pensa, não aumenta os custos, mas, isso sim, ajuda a racionalizá-los, diminuindo o número de exames e tratamentos desnecessários, e que existem profissionais qualificados para ajudá-los nessa tarefa.

O terceiro aspecto a ser considerado na inclusão da genética no serviço público de saúde é a atuação conjunta entre os Ministérios da Saúde e da Educação. A recente reforma curricular dos cursos de graduação flexibilizou os conteúdos, optando por sugerir temas a serem abordados na formação de novos profissionais (1). Dessa maneira, ao mesmo tempo que foi assegurada às instituições de ensino superior ampla liberdade na composição da carga horária a ser cumprida, indicam-se os campos de estudo e demais expe- 
riências de ensino-aprendizagem que comporão os currículos. No que diz respeito às ciências biológicas, dentro das profissões de saúde, a ênfase geral da genética é dada aos conteúdos, teóricos e práticos, de bases moleculares e celulares de processos normais e alterados (23). O resultado dessa orientação é o ensino da genética molecular, na maioria das vezes em detrimento dos princípios básicos da hereditariedade, da genética clássica e da correlação genótipo/fenótipo na genética humana. Assim, formam-se profissionais que conhecem os ácidos nucleicos, seu funcionamento e técnicas para seu estudo, mas desconhecem conceitos como síndrome, parádrome, sequência, fenocópia, genocópia, penetrância, expressividade e outros, necessários para o entendimento da origem da doença genética, seu grau de hereditariedade, prognóstico e tratamento. É preciso enfatizar a importância desses conhecimentos para a formação de todos os profissionais de saúde. O conhecimento da terminologia básica em genética, de padrões de herança, da interação genética/ambiente/ comportamento no aparecimento e tratamento das doenças, da diferença entre diagnóstico clínico e identificação de predisposição genética, assim como a habilidade para fazer heredogramas e para identificar pacientes que podem se beneficiar de serviços de genética, além de consciência da natureza confidencial das informações genéticas, são algumas das competências básicas preconizadas internacionalmente para todos os profissionais de saúde (24).

A formação de especialistas em genética está sendo abordada de diversas maneiras em diferentes países. Em alguns, como a Turquia, a educação nessa área se estende às parteiras, cuja maioria quase absoluta não tem nível superior (1). No Brasil, não há iniciativas de formação continuada de profissionais que atuam na área de saúde, um dado altamente significativo. A difusão do conhecimento genético cabe a todas as instituições de ensino superior, seja na área de saúde, seja na de humanidades e na de direito. $\mathrm{O}$ rito de atendimento ao paciente em genética, assim como em todas as áreas da saúde e outras áreas, e a realização de exames, demandam um instrumento chamado "termo de consentimento livre e esclarecido". Como haver consentimento livre se as implicações e detalhes não podem ser suficientemente esclarecidos, inclusive quando da assistência legal e psicológica, por exemplo? Como haver consentimento esclarecido se, às vezes, o próprio profissional de saúde não tem ciência da enorme dimensão social do ato a ser praticado?

Partindo da premissa de que o avanço do conhecimento na área de genética afeta todas as pessoas, independentemente da profissão, é indispensável que pelo menos os profissionais de nível superior estejam cientes desse fato para enfrentar suas responsabilidades de cunho profissional, pessoal e social. A introdução desses conhecimentos no currículo da segunda metade do ensino fundamental e no ensino médio seria altamente desejável, não somente por garantir o conhecimento a quem não pretende ou não consegue ingressar no ensino superior, mas também por formar a base sobre a qual o profissional de saúde construirá seu con- hecimento em genética humana. É responsabilidade do Ministério da Educação introduzir esses conteúdos nas diretrizes curriculares para o ensino fundamental e médio no contexto do Plano Nacional de Educação.

Finalmente, é necessário delimitar espaços, definir quem faz o que, fomentar o trabalho em equipe, reconhecer as atribuições profissionais do conselheiro genético, do geneticista molecular, do citogeneticista e do médico geneticista. Afinal, o campo da genética cresceu, se agigantou, se desdobrou; não é possível, nem faz sentido, uma pessoa ser especialista em todas as áreas dessa ciência.

Pesquisas recentes realizadas no Sul e Nordeste do Brasil sobre o ensino de genética aos profissionais de saúde apontam que, no primeiro caso, até 95\% dos cursos de formação de profissionais de saúde incluem a disciplina de genética no currículo (25). No caso do Nordeste, apenas $34,74 \%$ dos cursos incluem essa disciplina (1). Mesmo considerando as diferenças metodológicas (na Região Sul foram pesquisados seis cursos, na Região Nordeste, 10), a disparidade é significativa e reflete a realidade mostrada por outras pesquisas, inclusive os números do CONASS. Serve ainda como um indicador inicial sobre onde concentrar os esforços de formação de geneticistas. Note-se que, na área da medicina, onde o conhecimento de genética humana é considerado imprescindível, a Universidade Federal da Bahia, localizada no Nordeste, apesar de abrigar diversos grupos de pesquisa em genética médica, oferece essa disciplina apenas de forma optativa, o que ocorre também na Universidade Federal de Pernambuco (1).

É função do Ministério da Educação a difusão do conhecimento genético entre os profissionais de saúde, no volume necessário para atender à população, no que diz respeito aos critérios para formação de novos especialistas e de organização e regulamentação das especializações dentro da genética humana. Já o Ministério da Saúde, em conjunto ou não com o de Educação, pode estruturar e promover cursos dentro do conceito da educação permanente para os profissionais já formados, oferecendo-os de forma contínua ao longo do ano, durante vários anos, no tempo suficiente para conseguir atualizar a maioria dos profissionais. Por outro lado, cabe a ambos, Ministério de Educação e Ministério da Saúde, integrar as unidades de genética já em funcionamento em uma rede, constituída por instituições tais como escolas de medicina, hospitais-escola, laboratórios e institutos de pesquisa em genética para, em um esforço conjunto, dar o enorme salto exigido para a universalização dos serviços de genética. As instituições estaduais de ensino superior, como a Universidade de São Paulo (USP) e a Universidade Estadual de Campinas (UNICAMP), e outras que possuem serviços de genética, poderiam ser convocadas para se integrar a essa rede. Outras instituições que já funcionam com unidades distribuídas também podem fazer parte. É o caso da Fundação Oswaldo Cruz, com seus institutos e suas unidades espalhadas pelo País, bem como da Rede SARAH de Hospitais de Reabilitação instituição pública de gerencia autônoma, com nove 
unidades em diferentes estados, que trata algumas doenças geneticamente determinadas, possui laboratórios de citogenética e genética molecular do mais alto nível e, infelizmente (pelo menos na Bahia), não admite estagiários nem realiza exames para outros centros. Além dessas, organizações não públicas que dispõem de laboratórios e centros de atendimento, como é o caso das APAEs em diversos estados do País, podem ainda compor essa rede. Num estágio mais avançado de cidadania, caberia a elas, associações, também a promoção e financiamento de estudos e pesquisas nas respectivas áreas de interesse.

Finalmente, as associações de genética, formadas por geneticistas humanos e médicos da mais alta qualidade, podem produzir peças educativas tanto para os profissionais de saúde como para os afetados por doenças genéticas e seus familiares e podem promover cursos de divulgação desse conhecimento. Urge destinar uma verba para incentivar geneticistas, no âmbito universitário, a elaborar materiais de difusão destinados a cursos de educação permanente para as diversas profissões, e de divulgação científica para públicos mais ampliados.

$O$ resultado de um tal esforço conjunto e, principalmente, da regulamentação da atividade de geneticista humano e de conselheiro genético, seria presumivelmente visível nos exames para título de especialista, tanto da Sociedade Brasileira de Genética como da Sociedade Brasileira de Genética Médica, que deverão sair do triste nível de um ou dois candidatos por ano para um número mais significativo que, embora de forma lenta, ajude a suprir as necessidades do País. Ao mesmo tempo, o Estado, convocando geneticistas humanos e médicos com o propósito de universalizar o atendimento básico em genética, promoverá o aparecimento e a identificação daqueles profissionais já qualificados, porém em inatividade.

Esse terceiro desafio identificável, e talvez o mais importante, encontra-se então na área da educação, da formação de novos profissionais, da integração e atualização daqueles já formados. É um desafio que requer esforços conjuntos com diversos segmentos da sociedade e organização política e social. Aqui é que se percebe com mais clareza a necessidade de amadurecimento social, pois trabalhar em conjunto significa reconhecer o valor e a sabedoria do outro, significa não entrar a priori com a condição de ser chefe da equipe, significa aprender a ouvir o outro - afinal, alguém que se propõe a fazer aconselhamento genético precisa ser capaz de escutar sensivelmente, reconhecer e aceitar o que outro tem a dizer; significa contribuir, somar. Na realidade, esse é o grande desafio. Os profissionais de saúde, principalmente médicos, precisam evoluir do sistema piramidal, hierárquico de organização dos serviços de saúde para o sistema horizontal. As ciências da saúde vêm se complexificando, diversificando e se organizando em diferentes áreas. A sociedade evoluiu em conhecimento e conquistas para a cidadania, ampliando as possibilidades do direito de escolha. Hoje muitos preferem terapias alternativas a terapias alopáticas. O senso comum e os saberes tradi- cionais e culturais ganharam significado e força mesmo dentro do contexto da modernidade. Não há como ignorar essas mudanças.

$\mathrm{O}$ acúmulo do conhecimento em biologia humana, patologias e história natural das doenças reforçou a estrutura das ciências médicas como uma área multidisciplinar, na qual cada profissional de saúde tem seu campo de atuação definido, com algumas áreas sendo transversais a várias profissões. É o caso do aconselhamento genético. Como consequência, muitas das medidas terapêuticas indicadas para a recuperação da saúde se situam dentro de outras disciplinas e dentro da área de atuação de profissionais de saúde não médicos. A medicina também depende, cada vez mais, dos profissionais não médicos para o diagnóstico e o prognóstico de doenças. Isso é especialmente verdade para as doenças de origem genética. Esse fato, no mínimo, abala o paradigma do médico como único responsável pelo diagnóstico e força o profissional a trabalhar em equipe, promovendo o desdobramento das responsabilidades não apenas profissionais, mas também sociais, nas ciências da saúde, deixando para trás as formas autoritárias e hierárquicas históricas da medicina, que ainda hoje são exercidas e que, na prática, prejudicam a sociedade.

\section{PROBLEMAS OPERACIONAIS}

Na área operacional é importante a distinção entre aquela parte da genética que é importante e aplicável à saúde pública e aquela que ainda é objeto de pesquisa; entre os exames de genética que realmente podem contribuir para a melhora do paciente e aqueles que apenas apontam a origem de problemas para os quais ainda não há solução; e entre as terapias em fase de experimentação e as já consolidadas. O desequilíbrio relacionado à pesquisa aplicada no âmbito laboratorial, em contraposição à sua aplicação no âmbito clínico, no caso da genética, ocorre porque a parte laboratorial, impulsionada pela pesquisa genômica e pelas suas implicações econômicas, teve um desenvolvimento muito mais rápido do que a pesquisa referente ao tratamento clínico. Muitas vezes é possível identificar uma alteração no material genético, causadora de determinada patologia, localizá-la, através de custosas e altas tecnologias, em nível de número de base e lugar no cromossomo, mas é impossível fazer alguma coisa que mude o curso da doença. É necessário, portanto, identificar, entre as patologias ocorrentes no País, quais têm protocolo de tratamento estabelecido e quais estão ainda em fase de pesquisa. Não que essas últimas não devam atendidas, porém não devem utilizar recursos alocados para a saúde, e sim recursos de pesquisa. Isso é de fundamental importância para um sistema universal de saúde, pois os recursos, além de escassos, são finitos.

Fazer da assistência em genética uma parte do SUS implica em oferecer essa assistência na atenção básica, ou seja, em programas desenvolvidos localmente, como ocorre no Programa de Saúde da Família (PSF). O PSF poderia ter na sua equipe um profissional 
de saúde com conhecimentos de genética para colaborar na prevenção, reconhecer doenças genéticas, levantar heredogramas, orientar o planejamento familiar, informar sobre a origem genética das doenças encontradas, informar a comunidade sobre teratógenos e a maneira de evitá-los e sobre nutrientes necessários e que influenciam malformações ou prejudicam o desenvolvimento e, não menos importante, manter registros atualizados das doenças genéticas encontradas. É esse atendimento primário que alimenta o atendimento secundário e terciário. É através do trabalho no atendimento primário que se vai conhecer o tipo de enfermidade genética incidente em cada região, o que, para um país com as dimensões territoriais e a heterogeneidade humana do Brasil, é absolutamente necessário para orientar a priorização em termos de atendimento e programas de triagem em cada região.

\section{A GENÉTICA HUMANA NO SUS}

O atendimento em genética não está totalmente ausente no SUS. De fato, a genética já está inclusa no SUS desde 1989. Apesar de a portaria 81 do Ministério da Saúde ter sido publicada em 2009, existem programas implantados há mais de 20 anos, tanto pelo Ministério da Saúde como por entidades beneficentes e filantrópicas. Mais uma vez, a demanda da sociedade favoreceu a inclusão da genética nos serviços de saúde.

O programa oficial mais antigo é aquele que atende as pessoas portadoras de deficiências. Em conformidade com o artigo 23, inciso II, da Constituição de 1988, a saúde e a assistência pública das pessoas portadoras de deficiências fica a cargo do Governo Federal, dos estados, do Distrito Federal e dos municípios (2). Nesse sentido, o Governo Federal, com a participação de representantes de instituições profissionais e usuários da área, formulou a Política Nacional de Saúde da Pessoa com Deficiência, com destaque para a lei $7853 / 1989$, que dispõe sobre o apoio e os cuidados à saúde da pessoa com deficiência e cria uma rede de serviços especializados em habilitação e reabilitação, garantindo acesso aos estabelecimentos de saúde e ao tratamento adequado. Dentre as diretrizes da política nacional de saúde da pessoa portadora de deficiência (26), encontramos, no título referente à prevenção, que o Estado promoverá

(...) o acesso da população aos exames mais específicos para detecção de doenças genéticas que determinam deficiência, com destaque para o exame de cariótipo e pesquisa para outros erros inatos do metabolismo em geral, tais como: fenilcetonúria, hemoglobinopatias, hipertiroidismo congênito, entre outras. Deverão ser também promovidos serviços de genética clínica para que se proceda a um adequado aconselhamento genético às famílias (. . ) (p. 36).

Tudo isso está incluído no SUS, cuja porta de entrada é a unidade básica de saúde.

Entretanto, quando o governo publicou o conjunto de portarias que permitem operacionalizar essa política (27), esqueceu de incluir, no item recursos humanos, a figura de conselheiro genético, geneticista humano ou médico geneticista, inviabilizando sua própria diretriz política. Essa figura não é mencionada nem mesmo nas portarias que tratam especificamente de doenças de origem genética, como a distrofia muscular progressiva (portaria MS/GM 1531 de 4 de setembro de 2001). Na portaria referente à osteogênese imperfeita - portaria 2305 de 19 de dezembro de 2001 - a opção de geneticista médico integrante da equipe multiprofissional é apresentada junto a um leque de outras especialidades médicas. Na atenção à saúde auditiva, as portarias MS/GM 2 073, de 28 de setembro de 2004, e MS/SAS 587, de 13 de outubro de 2004, que regulamentam as políticas oficiais nessa área, mesmo considerando síndromes genéticas e malformações craniofaciais como causas de surdez classificadas dentro do atendimento de média e alta complexidade, não prevêem consulta a geneticista (27).

A triagem neonatal foi implantada no Brasil com a portaria GM/MS 822 de 6 de junho de 2001, que prevê a triagem, pela técnica de papel de filtro, da fenilcetonúria, hipotireoidismo, doença falciforme e fibrose cística em todos os recém-nascidos. Conhecida no País como "teste do pezinho", no Estado da Bahia a triagem ocorre em praticamente todos os municípios (28). Em cada estado, um centro de referência é encarregado de convocar os neonatos que apresentam resultados alterados, fazer exames específicos, providenciar orientação e aconselhamento genético às famílias dos afetados, suplementos alimentares no caso da fenilcetonúria e medicamentos no caso do hipotireoidismo. O nível de implantação difere em cada estado e os laboratórios envolvidos são públicos, mas a participação de laboratórios privados não é vedada.

As APAEs também prestam serviços à população, mantendo ambulatórios, laboratórios, escolas especializadas, centros de profissionalização, centros de fisioterapia e fazendo o acompanhamento das crianças com atraso de desenvolvimento psicomotor. Outras associações dedicam-se especialmente ao acompanhamento e cuidado das pessoas com síndrome de Down.

O poder legislativo também apresentou uma iniciativa no sentido de incluir a genética no atendimento do SUS, acrescentando um dispositivo à lei 9623 de 12 de janeiro de 1996, que regula o item 7 do artigo 226 da Constituição Federal e que trata do planejamento familiar, estabelece penalidades e dá outras providências. O dispositivo apresentado assegura o aconselhamento genético, no ato do planejamento familiar, nos casos em que haja indicação clínica (29). Esse acréscimo foi aprovado em agosto de 2009 e tinha, inicialmente, prazo de 1 ano para ser implementado.

\section{DIFUSÃO E TRANSPARÊNCIA}

Dentre as ações que visam a divulgação do conhecimento e sua aplicação na prática clínica e que contribuem para a formação continuada do profissional de medicina, temos o Projeto Diretrizes (30). Essa iniciativa da Associação Médica Brasileira (AMB) e do Con- 
selho Federal de Medicina em conjunto com a Agência Nacional de Saúde Suplementar, que é um órgão do Ministério da Saúde, promove a elaboração de diretrizes diagnósticas, terapêuticas e preventivas baseadas em evidências científicas destinadas a qualificar a assistência prestada nesse setor, fornecendo documentação para que o profissional de saúde embase suas decisões clínicas. O diferencial dessas orientações é seu caráter diretivo, traduzido em recomendações claras e implementáveis, mas ao mesmo tempo flexíveis o bastante para prever o diferente e o pouco usual. Embora o seu objetivo principal não seja educacional, e sim o de unificar e subsidiar o profissional médico em sua atuação, evitando possíveis conflitos judiciais, o resultado é também educativo. A elaboração das diretrizes ficou a cargo das sociedades de especialidades, sob a coordenação de um grupo de revisores da AMB.

$\mathrm{O}$ projeto já publicou diretrizes para a anamnese, exames laboratoriais, diagnóstico e tratamento de algumas doenças de origem genética (30). É interessante observar que somente algumas dessas diretrizes foram redigidas por membros da Sociedade Brasileira de Genética Médica. Embora não sejam diretrizes elaboradas especificamente para o sistema público de saúde, elas estão disponíveis para consulta via Internet e qualquer profissional interessado pode usá-las. Sendo um projeto em andamento, novas diretrizes são incluídas frequentemente.

Dentre os programas que trabalham para a construção do conhecimento em genética humana destaca-se, além daqueles de pesquisa sediados nas universidades públicas, o Estudo Colaborativo LatinoAmericano de Malformações Congênitas, que fornece uma boa base de dados epidemiológicos nesta área. Infelizmente, os dados se limitam àqueles provenientes de um número relativamente pequeno de instituições integrantes do programa no Brasil. O Instituto Nacional de Genética Médica Populacional, com sede no Estado de Rio Grande do Sul e formado por seis instituições de três estados, tem como atividade principal a pesquisa, mas atua também na divulgação do conhecimento genético via produção de peças específicas e do atendimento à população, médica e não médica, através do sistema de informação sobre agentes teratogênicos.

Finalmente, partindo do princípio de que a democracia se constrói com transparência de ações e que, no caso da pesquisa em genética humana, essa transparência é essencial para que sociedade, pacientes e profissionais de saúde se beneficiem e participem do próprio processo de pesquisa, e considerando-se as responsabilidades sociais, científicas e profissionais das organizações sociais voltadas para a pesquisa, a formação e o desenvolvimento de áreas científicas e profissionais, seria de alto valor a disponibilização de links nos sites das associações de geneticistas que permitam consultar informações sobre cursos de formação, sites de difusão e, especialmente, sobre doenças genéticas que estão sendo pesquisadas, qual o nível de pesquisa (diagnóstico, tratamento, desenvolvimento de fármacos, epidemiológica, etc.) em execução, qual seu período de duração, condições para participação e disponibilidade para realizar testes diagnósticos dessa doença específica, e-mail para contato e outras informações úteis para todos os profissionais de saúde.

Instrumentos como o Serviço de Informação sobre Agentes Teratogênicos (SIAT), além de divulgadores do conhecimento, são espaços educacionais, pois as pessoas que fornecem as informações precisam pesquisar a literatura e estar em constante atualização para poder exercer o seu papel corretamente. Por outro lado, as pessoas que as recebem, leigos ou profissionais, podem adquirir novos e valiosos conhecimentos sobre a fisiologia e embriologia humanas. Estudantes da saúde podem estagiar nessa área, agregando teratogenicidade, malformações congênitas e reprodução humana às suas áreas de atuação. A falta de divulgação do serviço e a falta de atendimento, quando solicitado, fazem com que esse sistema, em alguns lugares, não funcione a contento (31).

\section{CONCLUSÕES}

A ideia central deste artigo foi levantar a discussão sobre os diversos aspectos implicados na universalização dos serviços de genética no Brasil. Como foi enfatizado, são urgentes o reconhecimento e a regulamentação da profissão de conselheiro genético, aberta para todos os profissionais de saúde, pois, de acordo com a política definida, esse profissional é o pilar do atendimento em genética. É preciso que todas as instituições envolvidas na atividade de prevenção, diagnóstico, tratamento e acompanhamento de pacientes com doenças de origem genética e de formação de profissionais de saúde especialistas nesta área se unam, compartilhando informações, experiências e instalações.

Nos últimos 20 anos, a assistência em genética foi introduzida no SUS através de atos isolados, porém de grande alcance. Nada disso, porém, mobilizou as associações representativas de profissionais dessa área para solicitar o reconhecimento, a regulamentação e a organização legal das diversas especialidades que compõem o setor. Porém, o momento histórico é favorável a essa movimentação. O quadro analisado evidencia grandes lacunas. Há muito que fazer e apenas um caminho: todos juntos, mãos à obra!

\section{SYNOPSIS}

\section{Challenges for the universalization of clinical genetics: the Brazilian case}

The present article deals with the difficulties of introducing medical genetics as part of the Brazilian public Unified Health System (SUS). A national policy of comprehensive care in medical genetics was established in 2009, having genetic counseling as a central pillar. However, there are strategic limitations to the implementation of this policy: a dearth of genetic counseling training programs, the lack of knowledge concerning the number of professionals available 
to provide genetic counseling, and the likely low number of professionals available for the job. A joint effort by the ministries of health and education is desirable to foster genetics and genetic counseling training for all health professions. In addition, genetics must be introduced in government programs such as the Family Health Program (Saúde da Família), a measure that would allow a mapping of the incidence of genetic diseases in the country and the implementation of genetic counseling despite the size of the territory and the population heterogeneity. Lastly, the introduc- tion of medical genetics as part of the SUS depends on the engagement of medical and nonmedical professionals in horizontal teamwork, with a change in the hierarchy that has traditionally been at the foundations of health care.

Key words: genetics, medical; genetic couseling; Unified Health System; human resources formation; national health programs; Brazil.

\section{REFERÊNCIAS}

1. Novoa MC. Genética humana: sociedade, saúde e educação [tese]. Salvador: Universidade Federal da Bahia; 2008.

2. Cruz-Coke R. Historia de la genética latinoamericana en el siglo XX. Rev Med Chil. 1999:127(12):1524-32.

3. Brasil. Constituição da República Federativa do Brasil. Brasília: Senado Federal; 1988. Disponível em: http://www. planalto.gov.br/ccivil_03/constituicao/ constitui\%C3\%A7ao.htm. Acessado em 30 de dezembro de 2010.

4. Simões SAS. A estrutura legal do Sistema Único de Saúde: breve escorço sobre o Direito Constitucional Sanitário. Jus Navegandi. 2004;9(363). Disponível em: jus.uol.com.br/revista/texto/5420. Acessado em 17 de junho de 2009.

5. Brasil, Ministério da Saúde. Portaria 81/2009. Disponível em: ftp.saude.sp. gov.br/ftpsessp/bibliote/informe eletronico/2009/iels.jan.09/iels13/U PT-MS-GM-81_200109.pdf. Acessado em 4 de setembro de 2009.

6. Instituto Brasileiro de Geografia e Estatística. Contagem da população 2007. Disponível em: www.ibge.gov.br/home/ estatistica/populacao/contagem2007/ default.shtm. Acessado em 10 de dezembro de 2009.

7. Brasil, Conselho Nacional de Secretários de Saúde. Nota técnica 05/2007. Política nacional de atenção integral em genética clínica. Disponível em: www.conass.org. $\mathrm{br} / \mathrm{admin} /$ arquivos/NT05-07.pdf. Acessado em 12 de setembro de 2007.

8. Brunoni D. Estado atual do desenvolvimento dos serviços de genética médica no Brasil. Rev Bras Genet. 1997;20(Suppl 1):11-23.

9. Salzano FM. Saúde pública no primeiro e terceiro mundos: desafios e perspectivas. Cien Saude Colet. 2002;7(1):7-16.

10. Horovitz DDG, Cardoso MH, Llerena JC, Mattos RA. Atenção aos defeitos congênitos no Brasil: características do atendimento e propostas para a formulação de política públicas em genética médica. Cad Saude Publica. 2006;22(12): 2599-609.

11. Conselho Federal de Biologia. Legislação do CFBio. Disponível em: cfbio.gov. br/legislacao.php. Acessado em 28 de setembro de 2009.
12. Conselho Federal de Biomedicina. Legislação. Disponível em: www.cfbio medicina.org.br/legislacao.php. Acessado em 28 de setembro de 2009.

13. Conselho Federal de Enfermagem. Áreas de atuação. Disponível em: http://site. portalcofen.gov.br/node/4173. Acessado em 28 de setembro de 2009.

14. Sociedade Brasileira de Genética. Título de especialista. Disponível em: www. sbg.org.br/editalTitEspecialista.html. Acessado em 28 de setembro de 2009.

15. National Society of Genetic Counselors. Disponível em: www.nsgc.org. Acessado em 20 de janeiro de 2010

16. Canadian Association of Genetic Counselors. Disponível em: cagc-accg.ca. Acessado em 20 de janeiro de 2010.

17. Association of Genetic Nurses and Counselors. Disponível em: www.agnc. org.uk. Acessado em 20 de janeiro de 2010.

18. Australasian Society of Genetic Counselors. Disponível em: www.hgsa.com. au. Acessado em 20 de janeiro de 2010.

19. National Society of Genetic Counselors' Definition Task Force, Resta R, Biesecker BB, Bennett RL, Blum S, Hahn SE, et al. A new definition of Genetic Counseling: National Society of Genetic Counselors' Task Force report. J Genet Couns. 2006; 15(2):77-83.

20. Brunoni D. Aconselhamento genético. Cien Saude Colet. 2002; 7(1):100-7.

21. Penchaszadeh VB, Beiguelman B. Medical genetic services in Latin America: report of a meeting of experts. Rev Panam Salud Publica. 1998;3(6):409-20.

22. Kenen RH. Opportunities and impediments for a consolidating and expanding profession: genetic counseling in the United States. Soc Sci Med. 1997;45(9): 1377-86.

23. Brasil, Ministério da Educação. Diretrizes curriculares. Disponível em: http:// meclegis.mec.gov.br/index/busca/page/ 2 /pesquisa/diretrizes $\% 20$ curriculares \%20área\%20de\%20saúde/. Acessado em 25 de setembro de 2009.

24. National Coalition for Health Professional Education in Genetics. Core competencies in genetics for health professionals. Disponível em: http://www. nchpeg.org/index.php?option $=\mathrm{com}_{-}$ content\&view $=$ article\&id $=94 \&$ Itemid $=$ 84. Acessado em 13 de novembro de 2009.

25. da Rosa VL. Genética humana e sociedade: conhecimentos, significados e atitudes sobre a ciência da hereditariedade na formação de profissionais de saúde [tese]. Florianópolis: Universidade Federal de Santa Catarina; 2000.

26. Brasil, Ministério da Saúde, Secretaria de Atenção à Saúde. Política nacional de saúde da pessoa portadora de deficiência. Brasília: Editora do Ministério da Saúde; 2008.

27. Brasil, Ministério da Saúde, Secretaria de Atenção à Saúde. Departamento de ações programáticas estratégicas. Manual de legislação em saúde das pessoas com deficiência. Brasília: Editora do Ministério da Saúde; 2006.

28. Sarmento LM. Avaliação da cobertura do programa de triagem neonatal no Estado da Bahia no ano de 2006 e distribuição geográfica das hemoglobinopatias detectadas nesse período [monografia]. Salvador: Fundação de Tecnologia e Ciência; 2007.

29. Brasil. Lei 9 263/1996. Disponível em: www.pge.sp.gov.br/centrodeestudos/ bibliotecavirtual/dh/volume\%20i / plajlei9263.htm. Acessado em 20 de setembro de 2009.

30. Agência Nacional de Saúde Suplementar, Associação Médica Brasileira, Conselho Federal de Medicina. Diretrizes clínicas na saúde suplementar. Disponível em: www.projetodiretrizes.org.br/ ans/diretrizes.html. Acessado em 2 de outubro de 2009.

31. Toralles MB, Trindade BMC, Fadul LC, Peixoto Junior CF, de Santana MACC, Alves CA. Importância do serviço de informações sobre agentes teratogênicos, Bahia, Brasil, na prevenção de malformações congênitas: análise dos quatro primeiros anos de funcionamento. Cad Saude Publica. 2009;25(1):105-10.

Manuscrito recebido em 26 de março de 2010. Aceito em versão revisada em 26 de agosto de 2010. 